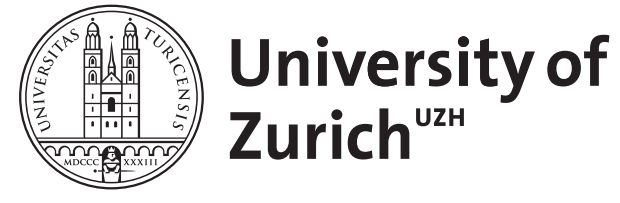
Archive

University of Zurich

University Library

Strickhofstrasse 39

CH-8057 Zurich

www.zora.uzh.ch

Year: 2009

\title{
Two types of classification in female alcoholism
}

Traber, R ; Würmle, O ; Modestin, J

DOI: https://doi.org/10.1007/s00737-009-0075-4

Posted at the Zurich Open Repository and Archive, University of Zurich

ZORA URL: https://doi.org/10.5167/uzh-25852

Journal Article

Published Version

Originally published at:

Traber, R; Würmle, O; Modestin, J (2009). Two types of classification in female alcoholism. Archives of Women's Mental Health, 12(5):291-299.

DOI: https://doi.org/10.1007/s00737-009-0075-4 


\title{
Two types of classification in female alcoholism
}

\author{
Rafael Traber • Othmar Würmle • Jiri Modestin
}

Received: 5 November 2008 / Accepted: 23 April 2009/Published online: 12 May 2009

(C) Springer-Verlag 2009

\begin{abstract}
Two types of alcoholism with distinct clinical features and mode of inheritance have been identified in male alcoholics. The relevant studies, however, have given consistent results in men but not in women. The current study tested the hypothesis that the type I and II classification is also valid in women. A sample of 103 hospitalised alcohol-dependent women were given face-toface structured interviews considering four different classification criteria sets devised for differentiation of alcoholism type I and II and type A and B along with SCID I and II. The two types of classification could be replicated with three of the four criteria sets, 73 women being allocated to the larger cluster $\mathrm{C} 1$, and 30 women to a smaller cluster $\mathrm{C} 2$. Comparing the patients from both clusters with each other, eight variables were identified which excellently discriminate between the groups. The two types of classification for alcoholism could also be found in a female sample. A type II of female alcohol-dependent patient was identified, characterized by parental alcoholism and paternal and patient's tendency for violent behavior. Type I lacks these characteristics. Early identification of the type II female alcoholic may be clinically important.
\end{abstract}

R. Traber $\cdot$ J. Modestin

Department of Psychiatry, Burghölzli Hospital,

University of Zurich,

Zurich, Switzerland

O. Würmle

Department of Psychiatry, Waldau Hospital, University of Berne, Berne, Switzerland

\section{J. Modestin $(\bowtie)$}

Zentrum für Angst- und Depressionsbehandlung Zürich,

Dufourstrasse 161,

CH-8008 Zurich, Switzerland

e-mail: jmodestin@zadz.ch
Keywords Alcohol dependence · Classification · Type I and II alcoholism · Type A and B alcoholism · Women

\section{Introduction}

Numerous attempts have been made to classify alcoholism (Babor and Lauerman 1986; Penick et al. 1999). Cloninger et al. (1981) identified two types of alcohol dependence, replicating these findings in an independent sample (Sigvardsson et al. 1996). They described a milieu-limited, less severe type I alcoholism which occurs in both sexes. The type II alcoholism is more severe, highly heritable, three times less frequent, and is said to occur only in men.

Other authors extended and elaborated the classification criteria set. Von Knorring et al. (1985a, 1985b) stressed the earlier onset and more social problems, Buydens-Branchey et al. (1989) the frequent suicidal and aggressive behaviour in type II alcoholics. Babor et al. (1992) described type B alcoholics, corresponding in many respects to type II alcoholics, and characterized additionally by a higher rate of comorbidity. There is a substantial overlap among these typologies; it has been argued that type I/type II typology may in fact reflect a simple late/early onset distinction, whereas severity of substance use may be the key factor for the type A/type B differentiation (Anthenelli et al. 1994; Schuckit et al. 1995; Epstein et al. 2002). Nevertheless, there appear to be two distinct broad types of alcoholism: type II, with an early onset and severe complications, and type I, with a late onset and a low prevalence of complications. These broad types have been repeatedly confirmed (Schuckit et al. 1995; Modestin and Würmle 1997). Some studies indicated more than two subtype classifications (Bucholz et al. 1996; Windle and Scheidt 2004); however, their results are inconsistent and the highly 
heterogeneous ongoing alcoholism research continues to refer to the two subtypes delineated above (e.g. Bogenschutz et al. 2006; Bottlender et al. 2006; Carpenter et al. 2006; Walter et al. 2006).

Female alcoholism is less frequent (Spak and Hallstrom 1995), and alcoholism and its classification have mostly been studied in men. In spite of the attempts to classify female alcoholism (Schuckit et al. 1969; Kubicka et al. 1992; Hill 1995; Hallman et al. 2001), the question of whether the proposed I/II and A/B subtypes also apply to female alcoholics remains largely unanswered. Cloninger et al. (1981) and Cloninger (1987) supposed female alcoholics to correspond to their milieu-limited type I alcoholism and, correspondingly, Bohman et al. (1981) did not find type II alcoholism in a small number of female adoptees. Glenn and Nixon (1991) found features of both types in the majority of female alcoholics, and similarly, Sannibale and Hall (1998) failed to replicate Cloninger's typology, because most alcohol dependent men and women met criteria for both types. On the other hand, Babor et al. (1992) identified $38 \%$ and Schuckit et al. (1995) $35 \%$ of their female alcoholic patients as suffering from type B alcoholism.

Thus, the individual results appear controversial and it is not known whether the sexes really differ in aspects of their alcoholism (Del Boca and Hesselbrock 1996). Therefore, the study of alcoholism typology in women is justified. Successful classification reduces the heterogeneity of expression of this complex disorder and helps understand its natural history and etiology (Johnson and Pickens 2001). Establishing types of female alcoholism is important for classification and treatment purposes; the goal of typology research is to identify alcoholism subtypes and to match each subtype with the most precise treatment strategy (Leggio et al. 2009). The aim of our study was to test the two types of alcoholism in female patients; based on our clinical experience we expected to find the type II / type B alcoholism also among women.

\section{Methods}

\section{Sample}

A total of 103 adult women, all of them participating in specialized voluntary inpatient alcoholism rehabilitation programs, were included in the study. They were all 18 to 65 years old; were hospitalized between September 2001 and December 2003; fulfilled the DSM-IV (1994) criteria for alcohol dependence; were not given any diagnosis of a comorbid psychotic (including bipolar) disorder according to DSM-IV (1994); were abstinent for more than two weeks; and were able to speak German well enough to complete a self-report questionnaire and to participate in an interview. At the time of the assessment, the patients were no longer suffering from withdrawal symptoms and were not cognitively impaired. Comorbid Axis I and II disorders were frequent (see Table 2) and $19.4 \%$ of the patients had a criminal record. Thus, the sample was composed of predominantly severe cases. Nevertheless, the patients were recruited in four different psychiatric hospitals and all consecutive admissions fulfilling the above mentioned criteria were included. The sample may be considered to be representative of alcohol-dependent women, seeking inpatient treatment in the greater area of Zurich.

\section{Measures}

A data set comprising 78 variables (including all variables presented in Table 1) was obtained for each patient during a semistructured clinical interview, covering sociodemographic, alcohol-use related, and clinical topics. Included were variables from four criteria sets, extracted from the descriptions in the published work of Cloninger (1987) and Cloninger et al. (1981, 1989), von Knorring et al. (1985a, 1987); Buydens-Branchey et al. (1989) and Babor et al. (1992), and devised by these authors for classification of alcoholism into the two above mentioned types. In the four columns of Table 1 the allocation of the individual criteria to the four criteria sets is presented. As can be seen, 23 to 28 criteria were considered for each set; some criteria were encountered in all four sets whereas some were encountered in only a single set.

The Structured Clinical Interview for DSM-IV Axis I disorders SCID-I (First et al. 1996) and for DSM-IV Axis II personality disorders (PD) SCID-II (First et al. 1997) was used in its German version (Wittchen et al. 1997). The SCID-I is a semi-structured interview for making the major Axis I DSM-IV diagnoses. The sections for affective disorders, psychotic disorders, substance abuse and anxiety disorders were used. The SCID-II covers all DSM-IV PDs (including early items of antisocial $\mathrm{PD}=$ conduct disorder items) and it adheres closely to DSM-IV diagnostic criteria. Using a SCID-II self-report personality questionnaire (SCIDII PQ) as a screening tool allows the clinician to inquire in the subsequent interview only about those items screened positive. False negative diagnoses in PD self-reports are extremely rare (Modestin et al. 1998). Different American and German studies have repeatedly shown that SCID - in its previous versions and in its present form - has satisfactory psychometric properties regarding its applicability, reliability, and efficiency (Wittchen et al. 1997).

\section{Procedure}

The local Ethical Committee had approved the study design. After obtaining the patients' informed written 
Table 1 Four criteria sets and the corresponding cluster characteristics

\begin{tabular}{|c|c|c|c|c|}
\hline Criteria set & $\begin{array}{l}\text { Cloninger et al. } \\
(1981,1987)\end{array}$ & $\begin{array}{l}\text { v. Knorring et al. } \\
(1985 a, 1987)\end{array}$ & $\begin{array}{l}\text { Buydens-Branchey } \\
\text { et al. (1989) }\end{array}$ & $\begin{array}{l}\text { Babor et.al. } \\
\text { (1992) }\end{array}$ \\
\hline n Cluster C1 & $67(65 \%)$ & $79(77 \%)$ & $62(60 \%)$ & $54(52)$ \\
\hline n Cluster C2 & $36(35 \%)$ & $24(23 \%)$ & $41(40 \%)$ & $49(48)$ \\
\hline \multicolumn{5}{|l|}{ Father } \\
\hline Alcohol abuse/dependence (\%) & $8 / 94 *$ & $27 / 75^{*}$ & $32 / 46$ & $35 / 41$ \\
\hline Treatment for alcoholism (\%) & $2 / 33^{*}$ & & & \\
\hline Violent behavior $(\%)$ & $12 / 56^{*}$ & & & \\
\hline Arrests for driving while intoxicated (\%) & $2 / 28^{*}$ & $4 / 33 *$ & & \\
\hline Criminal record $(\%)$ & $19 / 19$ & $3 / 17^{*}$ & & \\
\hline Treatment for depression $(\%)$ & & $13 / 13$ & & \\
\hline \multicolumn{5}{|l|}{ Mother } \\
\hline Alcohol abuse/dependence (\%) & $8 / 36^{*}$ & $14 / 29^{*}$ & $15 / 22$ & $6 / 31 *$ \\
\hline Treatment for alcoholism (\%) & $2 / 11^{*}$ & & & \\
\hline Violent behavior (\%) & $13 / 17$ & & & \\
\hline Treatment for depression $(\%)$ & & $23 / 58^{*}$ & & \\
\hline \multicolumn{5}{|l|}{ Patient } \\
\hline Age $(\mathrm{MN}, \mathrm{y})$ & & $46 / 38^{*}$ & & $43 / 45$ \\
\hline Marital status married (\%) & & & $40 / 27$ & \\
\hline Marital status divorced (\%) & & & $36 / 22$ & \\
\hline Marital status single $(\%)$ & & & $24 / 51^{*}$ & \\
\hline Professional qualification (\%) & & & $85 / 76$ & \\
\hline Living alone $(\%)$ & & & $58 / 49$ & \\
\hline Working during last 3 months (\%) & & & $29 / 20$ & $33 / 16^{*}$ \\
\hline Age at 1st alcohol intake (MN, y) & $17 / 17$ & $18 / 16$ & $17 / 18$ & $17 / 18$ \\
\hline Absences at work due to alcohol intake (\%) & $40 / 69^{*}$ & $46 / 67^{*}$ & & \\
\hline Age at 1 st regular alcohol intake $(\mathrm{MN}, \mathrm{y})$ & $30 / 24^{*}$ & $30 / 23^{*}$ & & $23 / 30$ \\
\hline Age at 1 st acknowledging alcohol problem $(\mathrm{MN}, \mathrm{y})$ & & $38 / 30^{*}$ & $37 / 33^{*}$ & $30 / 38$ \\
\hline Age at 1 st inpatient therapy for alcoholism $(\mathrm{MN}, \mathrm{y})$ & $42 / 37^{*}$ & $42 / 33^{*}$ & & $41 / 47$ \\
\hline Age at 1 st outpatient therapy for alcoholism (MN, y) & $40 / 37$ & $40 / 32$ & $41 / 35$ & $37 / 40$ \\
\hline 1st inpatient therapy $(\%)$ & $36 / 42$ & $35 / 46$ & $44 / 29$ & $37 / 39$ \\
\hline Job loss due to alcohol intake (\%) & & $38 / 70^{*}$ & & $61 / 26^{*}$ \\
\hline Loss of partner due to alcohol problem (\%) & & & & $37 / 27$ \\
\hline Loss of control on alcohol intake (\%) & $24 / 19$ & & & \\
\hline Dysphoric while intoxicated (\%) & $43 / 46$ & & & $46 / 44$ \\
\hline Dysphoric while sober (\%) & $15 / 8$ & $14 / 8$ & $8 / 17$ & $22 / 7$ \\
\hline Feeling of guilt when drinking (\%) & $64 / 75$ & & & \\
\hline Accidents while intoxicated (\%) & & & $58 / 63$ & $67 / 53$ \\
\hline Violent behavior while intoxicated (\%) & $24 / 31$ & $22 / 42 *$ & $26 / 27$ & \\
\hline Arrests for driving while intoxicated (\%) & $28 / 28$ & $28 / 29$ & $31 / 24$ & \\
\hline Arrests while intoxicated (\%) & $13 / 28^{*}$ & $18 / 21$ & $15 / 24$ & \\
\hline Less than a year abstinent after last therapy (\%) & & & $92 / 87 *$ & \\
\hline Criminal record $(\%)$ & & $14 / 38^{*}$ & $16 / 24$ & $26 / 11 *$ \\
\hline Additional cannabis/hallucinogen abuse (\%) & & $5 / 71 *$ & & $26 / 14$ \\
\hline Additional sedatives/medication abuse (\%) & & $15 / 54^{*}$ & & $30 / 18$ \\
\hline Additional opioid/cocaine abuse (\%) & & $10 / 29^{*}$ & & $5 / 15$ \\
\hline Any additional abuse (\%) & $36 / 50$ & $29 / 80$ & $39 / 44$ & $50 / 31$ \\
\hline Suicide attempts $(\%)$ & & & $8 / 100^{*}$ & \\
\hline Repeated suicide attempts (\%) & & & $0 / 68 *$ & \\
\hline Serious suicide attempts $(\%)$ & & & $0 / 63 *$ & \\
\hline
\end{tabular}


Table 1 (continued)

\begin{tabular}{|c|c|c|c|c|}
\hline Criteria set & $\begin{array}{l}\text { Cloninger et al. } \\
(1981,1987)\end{array}$ & $\begin{array}{l}\text { v. Knorring et al. } \\
\text { (1985a, 1987) }\end{array}$ & $\begin{array}{l}\text { Buydens-Branchey } \\
\text { et al. (1989) }\end{array}$ & $\begin{array}{l}\text { Babor et.al. } \\
\text { (1992) }\end{array}$ \\
\hline Any anxiety disorder (\%) & & & & $6 / 70^{*}$ \\
\hline Social phobia (\%) & & & & $2 / 24 *$ \\
\hline Simple phobia $(\%)$ & & & & $0 / 20 *$ \\
\hline Panic disorder $(\%)$ & & & & $2 / 26^{*}$ \\
\hline Present depression $(\%)$ & & & & $54 / 92 *$ \\
\hline Previous therapy for depression (\%) & & $75 / 46^{*}$ & $58 / 83^{*}$ & $56 / 74 *$ \\
\hline Antisocial personality disorder (\%) & & & $7 / 15$ & $30 / 6$ \\
\hline Minimal brain dysfunction (\%) & $5 / 6$ & $5 / 4$ & $2 / 7$ & 4/ 1 \\
\hline
\end{tabular}

Data are presented for Cluster $\mathrm{C} 1 /$ Cluster $\mathrm{C} 2 ; \mathrm{MN}=$ mean, $y=$ years, $w=$ weeks; $*=$ contribution to cluster solution

consent for study participation, the patients completed the self-report questionnaire SCID-II PQ. In the first session, the patients were interviewed by one of the authors (RT), a psychiatrist with over 6 years' professional experience and a SCID trainer. The interview data covered the above mentioned 78 variables. In the second session, the Structured Clinical Interview for DSM-IV Axis I (SCID-I) and Axis II disorders (SCID-II) was carried out. All interviews were performed by the same interviewer to ensure the reliability of the assessments.

Data analysis

First, descriptive analysis of the data was performed. Afterwards, four cluster analyses (k-means type) were carried out with the four individual criteria sets mentioned above (23-28 variables in each of the sets, see Table 1). As the aim of the study was to replicate the two types of alcoholism, the two cluster solution was tested. The number of variables decisive for the individual cluster formations in Table 1 they are indicated by asterisks — was 10, 17, 7 and 10 respectively, considering only variables with higher F-values $(p<0.1)$. In three of the four analyses, two clusters were obtained; a cluster with a higher number of patients (larger cluster) and a cluster with a smaller number of patients (smaller cluster). In the cluster analysis with the criteria set of Babor et al. (1992), two clusters of almost the same size were found, dissimilar to the clusters obtained with the other three criteria sets. Therefore, the cluster membership obtained with this criteria set was excluded from further analyses.

Regarding the three positive sets, 79 (77\%) out of 103 patients belonged in all of them in a similar manner to the larger cluster C1 (59 patients) or the smaller cluster C2 (20 patients). The remaining 24 patients belonged in 2 of the 3 sets to the same - larger or smaller - cluster. All 103 study patients were then allocated to a common larger $(\mathrm{C} 1$, comprising 73 patients) or smaller (C2, comprising 30 patients) cluster according to their prevailing membership. Both groups were then compared with each other with the help of the stepwise discriminant analysis in order to identify, from a larger pool of 51 variables presented in Table 1, those most strongly contributing to the group formation. In the analysis, $p<0.05$ and $p<0.2$ were chosen for whether a variable should be entered into, or removed from the model respectively.

\section{Results}

The patients were 44 years old on average $(\mathrm{SD}=9$, range 23-62), 70\% single or divorced, with a professional qualification (81\%), but not regularly employed recently (76\%). Typically, they started their alcohol consumption aged 17 years $(\mathrm{SD}=6$, range $8-44)$ and their regular alcohol consumption aged 28 years $(\mathrm{SD}=11$, range $12-59)$. On average, they entered their first alcohol-related outpatient therapy at the age of 38 years $(\mathrm{SD}=10$, range $18-60)$ and their first inpatient therapy at the age of 40 years $(\mathrm{SD}=10$, range 18-60). An additional substance abuse/dependence was admitted by $41 \%$. Because of alcohol consumption $46 \%$ of the patients had lost their job and $32 \%$ their partner; $26 \%$ were violent and $60 \%$ had had accidents while intoxicated, and $19 \%$ had a criminal record. Family history revealed alcohol abuse/dependence in the patients' fathers in $38 \%$ and violent behaviour in $27 \%$; depression in the patients' mothers was indicated in $31 \%$, alcoholism in $18 \%$, and violent behaviour in $15 \%$. Table 2 shows the frequency of interview-based comorbid diagnoses. Suicide attempts were noted in $45 \%$ of the patients.

As mentioned, cluster analyses confirmed two cluster solutions with three of four individual criteria sets (Table 1), the larger cluster $\mathrm{C} 1$ having 67, 79, and 62 members and the smaller cluster $\mathrm{C} 2$ having 36, 24, and 41 members. Using the criteria set by Cloninger et al. (1981, 1989), the smaller cluster C2 was most prominently characterized by 
Table 2 Prevalences of comorbid Axis-I disorders, suicidal behavior and Axis-II disorders in 103 alcohol dependent women

\begin{tabular}{lc}
\hline Lifetime generalized anxiety disorder & $41(40 \%)$ \\
Lifetime panic disorder & $15(15 \%)$ \\
Lifetime simple phobia & $26(25 \%)$ \\
Lifetime social phobia & $20(19 \%)$ \\
Lifetime depressive disorder & $74(72 \%)$ \\
ADHD as a child & $5(3 \%)$ \\
ADHD as an adult & $3(3 \%)$ \\
Paranoid PD & $8(8 \%)$ \\
Schizoid PD & $0(0 \%)$ \\
Schizotypal PD & $2(2 \%)$ \\
Any PD Cluster A & $9(9 \%)$ \\
Histrionic PD & $0(0 \%)$ \\
Narcissistic PD & $1(1 \%)$ \\
Borderline PD & $20(20 \%)$ \\
Antisocial PD & $10(10 \%)$ \\
Any PD Cluster B & $24(24 \%)$ \\
Avoidant PD & $25(24 \%)$ \\
Dependent PD & $8(8 \%)$ \\
Obsessive-compulsive PD & $11(11 \%)$ \\
Any PD Cluster C & $36(35 \%)$ \\
Negativistic PD & $5(5 \%)$ \\
Depressive PD & $6(6 \%)$ \\
Any PD & $54(52 \%)$ \\
\hline
\end{tabular}

Frequencies are indicated

both parents' alcoholism and the father's violent behaviour, using the criteria set by von Knorring et al. (1985a, 1987) by patient's younger age when starting to drink and additional substance abuse, alcoholism in the father and depression in the mother. Considering the criteria set by Buydens-Branchey et al. (1989), C2 was most prominently characterized by the patient's suicidal behaviour and a history of depression.

In the cluster analysis with the criteria set proposed by Babor et al. (1992), two clusters of almost equal size (with 54 and 49 members) were found, incongruent with the other three cluster solutions. To check this result, we tested the agreement between the final clustering, based on the combined criteria set ( 73 patients in cluster $\mathrm{C} 1$ and 30 patients in cluster $\mathrm{C} 2$ ), and the clustering of the individual four criteria sets inferred from Cloninger et al. $(1981,1989)$; von Knorring et al. (1985a, 1987); Buydens-Branchey et al. (1989), and Babor et al. (1992). The kappa coefficients were $0.78,0.65,0.34$ and 0.01 respectively, confirming that the criteria set proposed by Babor et al. (1992) has a different structure than the three other criteria sets in female alcoholism.

In the stepwise discriminant analysis, the two groups of patients were compared with each other considering the whole pool of 51 variables shown in Table 1. The analysis yielded a model comprising 8 variables enabling optimal group allocation (Table 3). The discriminant function of the 8 variables proved to be very good: the Eigenvalue was 2.44 , which indicates a good discriminant function, the canonical correlation coefficient was 0.84 , which indicates a good distinction between the groups. The Wilks' Lambda value, indicating the degree of separation of the mean values of the discriminant function in both groups, was 0.29 $\left(\chi^{2}=119.96,8 \mathrm{df}, p<0.0001\right)$. Altogether, 96 of 103 patients could be correctly allocated to the appropriate cluster, both sensitivity and specificity being $93 \%$.

Finally, the distribution of PD types and PD clusters in both these groups was tested. In our type II group, there was an overrepresentation of antisocial PD (23\% vs $4 \%$; $\left.\chi^{2}=9.88,1 \mathrm{df}, p=0.007\right)$, borderline PD (33\% vs $14 \% ; \chi^{2}=$ $6.11,1 \mathrm{df}, p=0.047)$ and of cluster B PDs $(43 \%$ vs $17 \%$; $\chi^{2}=7.68,1 \mathrm{df}, p=0.006$ ),

\section{Discussion}

A sample of 103 hospitalized women, all of them having fulfilled the DSM-IV (1994) criteria for alcohol dependence, was studied. On average, these women showed longlasting alcohol dependence with a series of secondary negative psychosocial consequences. In all women alcohol was the main substance of abuse; however, additional substance abuse/dependence was found in about $40 \%$. Also, there was an important lifetime comorbidity with depressive (over $70 \%$ ), anxiety $(40 \%$ ), and personality disorders (about 50\%), avoidant PD and borderline PD being the most frequent. These findings are largely supported by those reported elsewhere (Hesselbrock et al. 1985; Ross et al. 1988; Nace et al. 1991; Kessler et al. 1997; Hallman et al. 2001).

Some authors (Bohman et al. 1981; Cloninger et al. 1981; Gilligan et al. 1988) assumed that female alcoholism was a unitary disorder and that type II alcoholism was limited to men. Four criteria sets, defining male alcoholism types and described by Cloninger et al. (1981, 1989); von Knorring et al. (1985a, 1987); Buydens-Branchey et al. (1989) and Babor et al. (1992) were tested in the present study. With the exception of Babor et al.'s (1992) criteria, we succeeded in classifying female patients into two subgroups of unequal size, type I being twice as large as type II. Multivariate stepwise discriminant analysis yielded eight variables (Table 3 ) best discriminating between the two types. They characterized the more severe type II alcoholism - in contrast to type I - by a greater likelihood of a) paternal alcoholism, physical violence and driving while intoxicated, b) maternal alcoholism, and c) patient's pathology in terms of comorbidity with cannabis/ 
hallucinogens/stimulants abuse or dependence, history of repeated suicide attempts, physical violence while intoxicated and arrests while intoxicated.

Thus, we were able to identify a type of female alcoholism (type II) with high familial alcoholism aggregation. Alcoholism runs in families (Cotton 1979) and there is a substance-specific genetic influence on alcoholism (0.5-0.6) in both sexes (Enoch and Goldman 2001). Women with a positive family history of alcoholism have increased negative outcomes of drinking (Pastor and Evans 2003) and familial density of alcoholism distinguished significantly between female non-alcoholics (8\%) and mild $(18 \%)$ and severe (33\%) alcoholics (Johnson and Pickens 2001). Our type II seems to have a higher genetic loading than type I, even though the father's alcoholism was identified as risk factors for female alcoholism in general (Kubicka et al. 1992).

A considerable proportion of our type II patients were violent and had been arrested while under the influence of alcohol. Cloninger et al.'s (1981) Type II alcoholism, characterized by paternal alcoholism and criminal behavior in the patient's father and the patient himself, was thought to be limited to male alcoholics. Our results demonstrate that this alcoholism type also exists in women. We could speculate that there may be epidemiological reasons (such as an increased prevalence of alcoholism in women in general) for the present identification of the type II and that this type of female alcoholism was less frequent in the past. Incidentally, the adoptees studied by Cloninger et al. (1981) were born between 1917 and 1939 in Sweden, where the legal regulations (Bratt system), in force during that period (1917 to 1955) considerably limited access to alcohol, especially for women. Also, age of first regular alcohol consumption seems to be lower in more recent birth cohorts, especially in women (Stoltenberg et al. 1999) and there is an association between an earlier onset of drinking and familial density of alcoholism (Dawson 2000; Hill et al. 2000).
There is a correspondence between our type II and type II alcoholics as characterized by von Knorring et al. (1985a) and Buydens-Branchey et al. (1989), who both included only male alcoholics in their investigations. Apart from paternal and maternal alcoholism, this correspondence concerns impulsiveness/aggressiveness while intoxicated, a high frequency of cannabis abuse and a history of suicide attempts. The history of repeated suicide attempts along with violent behaviour and arrests under the influence of alcohol could be tentatively interpreted as an expression of impulsivity, and a higher degree of impulsiveness was found to be more frequent in type II than in type I male alcoholics and healthy controls (Cloninger et al. 1989; von Knorring et al. 1987; Lykouras et al. 2004; Echeburúa et al. 2008). Associations between all these variables are known: associations between high alcohol use in women and high impulsivity (Poikolainen 2000; Grano et al. 2004), impulsivity and paternal alcoholism (Petry et al. 2002), impulsivity, violence, and suicide risk (Moussas et al. 1999; McGirr et al. 2006), female alcoholism, impulsiveness and additional substance misuse (Hallman et al. 2001).

In contrast, no relationship has been found between our typology and that of Babor et al. (1992). Major criteria that discriminate between Babor et al.'s type A and B, such as age of onset, psychiatric comorbidity with depression, anxiety, childhood disorders, antisocial PD and polydrug use, did not contribute to the type differentiation in our sample. We found a high comorbidity with affective, anxiety and personality disorders and with additional substance abuse, however, with the exception of cannabis/hallucinogens/stimulants abuse/dependence, comorbidity had no impact on the type formation. Johnson et al. (1998) identified three subgroups of alcoholics in a sample composed of both women and men: mild, severe and dissocial. Similarities between their severe group and our type II concern familial loading and comorbid drug dependence.

Several authors have proposed an alcoholism subtyping including the criterion of age of onset of drinking

Table 3 Result of the discriminant analysis and the distribution of final variables in both clusters

\begin{tabular}{|c|c|c|c|c|c|}
\hline Step Variable & $\begin{array}{l}\text { Wilks' } \\
\text { Lambda }\end{array}$ & Exact $\mathrm{F}$ & Significance & $\begin{array}{l}\text { Cluster } \\
\text { C1 }(n=73)\end{array}$ & $\begin{array}{l}\text { Cluster } \\
\text { C2 }(n=30)\end{array}$ \\
\hline 1 Father alcoholic & .54 & 87.01 & .000 & $12(16)$ & $27(90)$ \\
\hline 2 Patient cannabis/hallucinogens/stimulants abuse/dependence & .47 & 56.39 & .000 & $8(11)$ & $13(43)$ \\
\hline 3 Mother alcoholic & .42 & 44.68 & .000 & $6(8)$ & $12(40)$ \\
\hline 4 Father violent & .39 & 38.56 & .000 & $11(15)$ & $17(57)$ \\
\hline 5 Father arrests for driving while intoxicated & .36 & 32.07 & .000 & $1(1)$ & $10(33)$ \\
\hline 6 Patient repeated suicide attempts & .33 & 32.67 & .000 & $14(19)$ & $14(47)$ \\
\hline 7 Patient arrested while intoxicated & .30 & 32.07 & .000 & $10(14)$ & $9(30)$ \\
\hline 8 Patient violent while intoxicated & .29 & 28.72 & .000 & $16(22)$ & $11(37)$ \\
\hline
\end{tabular}


(Anthenelli et al. 1994; Hill 1995; Penick et al. 1999; Epstein et al. 2002). In this study, the variable "age of onset of drinking" did not contribute to the individual cluster solutions (Table 1) and it did not appear among the eight variables best discriminating between the types (Table 3). Nevertheless, age of drinking onset could covariate with other variables, appearing in the model: Familial density of alcoholism predicted an earlier onset of drinking ( Hill et al. 2000), women reporting early onset drinking scored higher on measures of impulsivity (Dougherty et al. 2004) and early onset of alcoholism was associated with increased risk for fights while drinking, drunk driving trouble and increased risk for other drug abuse (Stoltenberg et al. 1999).

In our investigation, the occurrence of antisocial PD did not contribute to the distinction of the two types - this in contrast to typologies that stress the presence of antisocial $\mathrm{PD}$ as a differentiating factor (Epstein et al. 2002) or even claim type II alcoholism to be a secondary disorder to antisocial PD (Sannibale and Hall 1998; Schuckit 1973). Nevertheless, Cluster B PDs including antisocial and borderline PD were overrepresented in our type II alcoholics, and sociopathic behaviour, represented by physical violence and the patient being arrested while intoxicated, contributed to the group information.

We are well aware of the limitations of our study, limitations which have to be considered when generalizing our findings. We used a relatively small and selected sample, restricted to treatment seeking, treatment motivated inpatients, from a particular geographic area. On the one hand, cluster sizes could have been influenced by the characteristics of the sample; especially severe, comorbid cases may be more likely to seek treatment. On the other hand, the inclusion of severe, comorbid cases may have enabled the identification of type II alcoholism in women. Our study was a cross-sectional study and only the two cluster solution was considered. Another cluster solution (e.g., a larger one) may possibly have provided a better fit to the data. There was no external validation for the clusters, and also, the use of stepwise analysis may capitalize on the unique characteristics of the sample. Therefore, our results should be considered as provisional and it would be desirable to validate our typology on another independent female sample.

In conclusion, the principal findings of this study can be summarized as follows:

1) Two types of alcoholism could be identified in women.

2) The relation between the two types was found to be $2: 1$ in women and thus similar to that found in men.

3) We succeeded in replicating the type I and type II classification in women using the criteria set proposed by Cloninger et al. $(1981,1989)$ and its modifications proposed by von Knorring et al. (1985a, 1987) and Buydens-Branchey et al. (1989).
4) Using these three criteria sets, most of the patients were allocated to the same cluster, which indicates a set concordance. In contrast, we could not replicate the type A and type B classification proposed by Babor et al. (1992) in a comparable way.

5) In a multivariate stepwise discriminant analysis, a set of 8 variables best defining the two types of female alcoholism could be identified. Surprisingly, this set did not include the age of alcoholism onset nor the Axis I and Axis II psychopathology.

6) Female alcoholism appears as heterogeneous as male alcoholism.

7) Our type II female alcoholic was characterized by a familiy history of alcoholism and behavioral pathology which could tentatively be interpreted in terms of impulsive behavior.

The classification presented in this paper could be important for research and also have clinical utility. The early identification of a more impulsive type of female alcoholic with familial alcoholism aggregation and, presumably, a higher corresponding genetic loading could help to initiate specific preventive measures, to improve treatment of this type of alcoholism by selecting specific interventions, and to better define the possible future course of illness.

\section{References}

American Psychiatric Association (1994) Diagnostic and Statistical Manual of Mental Disorders, 4th edn. American Psychiatric Association, Washington, DC

Anthenelli RM, Smith TL, Irwin MR, Schuckitt MA (1994) A comparative study of criteria for subgrouping alcoholics: the primary/secondary diagnostic scheme versus variations of the type 1/type 2 criteria. Am J Psychiatry 151:1468-1474

Babor F, Lauerman RJ (1986) Classification and forms of inebriety. Historical antecedents of alcohol typologies. In: Galanter M (ed) Recent developments in alcoholism. Plenum Press, New York London, pp 113-144

Babor TF, Hofmann M, DelBoca FK, Hesselbrock V, Meyer RE, Dolinsky ZS, Rounsaville B (1992) Types of alcoholics. Arch Gen Psychiatry 49:599-608

Bogenschutz MP, Tonigan JS, Miller WR (2006) Examining the effects of alcoholism typology and AA attendance on selfefficacy as a mechanism of change. J Stud Alcohol 67:562-567

Bohman M, Sigvardsson S, Cloninger CR (1981) Maternal inheritance of alcohol abuse. Cross-fostering analysis of adopted women. Arch Gen Psychiatry 38:965-969

Bottlender M, Preuss UW, Soyka M (2006) Association of personality disorders with Type A and Type B alcoholics. Eur Arch Psychiatry Clin Neurosci 256:55-61

Bucholz KK, Heath AC, Reich T, Hesselbrock VM, Kramer JR, Nurnberger JI Jr, Schuckit MA (1996) Can we subtype alcoholism? A latent class analysis of data from relatives of alcoholics in a multicenter family study of alcoholism. Alcohol Clin Exp Res 20:1462-1471 
Buydens-Branchey L, Branchey MH, Noumair D (1989) Age of alcoholism onset. Arch Gen Psychiatry 46:225-230

Carpenter KM, Liu XH, Hasin DS (2006) The Type A-Type B classification in a community sample of problem drinkers: structural and predictive validity. Addict Behav 31:15-30

Cloninger CR (1987) Neurogenetic adaptive mechanisms in alcoholism. Science 236:410-416

Cloninger CR, Bohman M, Sigvardsson S (1981) Inheritance of alcohol abuse. Cross-fostering analysis of adopted men. Arch Gen Psychiatry 38:861-868

Cloninger CR, Sigvardsson S, Gilligan SB, von Knorring AL, Riech T, Bohman M (1989) Genetic heterogeneity and the classification of alcoholism. Adv Alcohol Subst Abuse 7:3-16

Cotton NS (1979) The familial incidence of alcoholism: A review. J Stud Alcohol 40:89-116

Dawson DA (2000) The link between family history and early onset alcoholism: earlier initiation of drinking or more rapid development of dependence? J Stud Alcohol 61:637-646

Del Boca FK, Hesselbrock MN (1996) Gender and alcoholic subtypes. Alcohol Health Res World 20:56-66

Dougherty DM, Mathias CW, Tester ML, Marsh DM (2004) Age at first drink relates to behavioral measures of impulsivity: the immediate and delayed memory tasks. Alcohol Clin Exp Res 28:408-414

Echeburúa E, de Bravo Medina R, Aizpiri J (2008) Personality variables, psychopathological alterations and personality disorders in alcohol-dependent patients according to Cloninger's typology of alcohol abuse. Psicothema 20:525-530

Enoch MA, Goldman D (2001) The genetics of alcoholism and alcohol abuse. Curr Psychiatry Rep 3:144-151

Epstein EE, Labouvie E, McCrady BS, Jensen NKI, Hayaki J (2002) A multi-site study of alcohol subtypes: classification and overlap of unidimensional and multidimensional typologies. Addiction 97:1041-1053

First MB, Spitzer RL, Gibbon M, Williams JBW (1996) Structured Clinical Interview for DSM-IV Axis I Disorders, Clinician Version (SCID-CV). American Psychiatric Press, Washington, $\mathrm{DC}$

First MB, Gibbon M, Spitzer RL, Williams JBW, Benjamin LS (1997) Structured Clinical Interview for DSM-IV Axis II Disorders, (SCID-II). American Psychiatric Press, Washington, DC

Gilligan SB, Reicht T, Cloninger CR (1988) Alcohol-related symptoms in heterogeneous families of hospitalized alcoholics. Alcohol Clin Exp Res 12:671-678

Glenn SW, Nixon SJ (1991) Application of Cloninger's subtypes in a female alcoholic sample. Alcohol Clin Exp Res 15:851-857

Grano N, Virtanen M, Vahtera J, Elovainio M, Kivimaki M (2004) Impulsivity as predictor of smoking and alcohol consumption. Personality Individ Differences 37:1693-1700

Hallman J, Persson M, af Klinteberg B (2001) Female alcoholism: Differences between female alcoholics with and without a history of additional substance misuse. Alcohol Alcohol 36: 564-571

Hesselbrock MN, Meyer RE, Keener JJ (1985) Psychopathology in hospitalized alcoholics. Arch Gen Psychiatry 45:1050-1055

Hill SY (1995) Neurobiological and clinical markers for a severe form of alcoholism in women. Alcohol Health Res World 19: 249-256

Hill SY, Shen S, Lowers L, Locke J (2000) Factors predicting the onset of adolescent drinking in families at high risk for developing alcoholism. Biol Psychiatry 48:265-275

Johnson EO, Pickens RS (2001) Familial transmission of alcoholism among nonalcoholics and mild, severe, and dissocial subtypes of alcoholism. Alcohol Clin Exp Res 25:661-666

Johnson EO, van den Bree MBM, Gupman AE, Pickens RW (1998) Extension of a typology of alcohol dependence based on relative genetic and environmental loading. Alcohol Clin Exp Res 22:1421-1429

Kessler RC, Crum RM, Warner LA, Nelson CB, Schulenberg J, Anthony JC (1997) Lifetime co-occurrence of DSM-III-R alcohol abuse and dependence with other psychiatric disorders in the national comorbidity survey. Arch Gen Psychiatry 54: 313-321

Kubicka L, Csemy L, Kozeny J (1992) A case-control study of risk factors of alcohol misuse in Czech women: are there four types of female alcoholism? Int J Addictions 27:1105-1118

Leggio L, Kenna GA, Fenton M, Bonenfant E, Swift RM (2009) Typologies of alcohol dependence. From Jellinek to genetics and beyond. Neuropsychol Rev 19:115-129

Lykouras L, Moussas G, Botsis A (2004) Examination of type I/type II alcoholism typology in a Greek hospital treatment population. Eur Psychiatry 19:214-218

McGirr A, Seguin M, Renaud J, Benkelfat C, Alda M, Turecki G (2006) Gender and risk factors for suicide: evidence for heterogeneity in predisposing mechanisms in a psychological autopsy study. J Clin Psychiatry 67:1612-1617

Modestin J, Würmle O (1997) Two types classification of male alcoholism confirmed. Eur Psychiatry 12:335-341

Modestin J, Erni T, Oberson B (1998) A comparison of self-report and interview diagnoses of DSM-III-R personality disorders. Eur J Personality 12:445-455

Moussas GI, Dadoutis G, Botsis A, Lykouras L (1999) Impulsivity, suicide and violence risk in hospitalized alcoholics: Sex differences. Psychiatriki 10:228-235

Nace EP, Davis CW, Gaspari MD (1991) Axis II comorbidity in substance abusers. Am J Psychiatry 148:118-120

Pastor AD, Evans SM (2003) (2003) Alcohol outcome expectancies and risk for alcohol use problems in women with and without a family history of alcoholism. Drug Alcohol Depend 70:201214

Penick CP, Nickel EJ, Powell BJ, Liskow BI, Campell J, Dale TM, Hassanein RE, Noble E (1999) The comparative validity of eleven alcoholism typologies. J Stud Alcohol 60:188-202

Petry NM, Kirby KN, Kranzler HR (2002) Effects of gender and family history of alcohol dependence on a behavioural task of impulsivity in healthy subjects. J Stud Alcohol 63:83-90

Poikolainen K (2000) Risk factors for alcohol dependance: A casecontrol study. Alcohol Alcohol 35:190-196

Ross HE, Glaser FB, Stiasny S (1988) Sex differences in the prevalence of psychiatric disorders in patients with alcohol and drug problems. Br J Addict. 83:1179-1192

Sannibale C, Hall W (1998) An evaluation of Cloninger's typology of alcohol abuse. Addiction 93:1241-1249

Schuckit MA (1973) Alcoholism and sociopathy - diagnostic confusion. Q J Stud Alcohol 34:157-164

Schuckit MA, Pitts FN, Reich T, King LJ, Winokur G (1969) Alcoholism. Two types of alcoholism in women. Arch Gen Psychiatry 20:301-306

Schuckit MA, Tipp JE, Smith TL, Schappiro E, Hesselbrock VM, Bucholz KK, Reich T, Nussberger JI Jr (1995) An evaluation of Type A and B alcoholics. Addiction 90:1189-1203

Sigvardsson S, Bohman M, Cloninger CR (1996) Replication of the Stockholm adoption study of alcoholism. Confirmatory crossfostering analysis. Arch Gen Psychiatry 53:681-687

Spak F, Hallstrom T (1995) Prevalence of female alcohol dependence and abuse in Sweden. Addiction 90:1077-1088

Stoltenberg SF, Hill EM, Mudd SA, Blow FC, Zucker RA (1999) Birth cohort differences in features of antisocial alcoholism among men and women. Alcohol Clin Exp Res 23:1884-1891

von Knorring AL, Bohman M, von Knorring L, Oreland L (1985a) Platelet MAO activity as a biological marker in subgroups of alcoholism. Acta Psychiat Scand 72:51-58 
von Knorring L, Palm U, Andersson HE (1985b) Relationship between treatment outcome and subtype of alcoholism in men. J Stud Alcohol 46:388-391

von Knorring L, von Knorring AL, Smigan L, Lindberg U, Edholm M (1987) Personality traits in subtypes of alcoholics. J Stud Alcohol 48:523-527

Walter H, Ramskogler-Skala K, Dvorak A, Gutierrez-Lobos K, Hartl D, Hertling I, Munda P, Thau K, Lesch OM, De Witte P (2006) Glutamic acid in withdrawal and weaning in patients classified according to Cloninger's and Lesch's typologies. Alcohol Alcohol 41:505-511

Windle M, Scheidt DM (2004) Alcoholic subtypes; are two sufficient? Addiction 99:1508-1519

Wittchen HU, Zaudig M, Fydrich T (1997) SKID Strukturiertes Klinisches Interview für DSM-IV Achse I und II, Handanweisung [Structured Clinical Interview for DSM-IV Axis I and II, guide]. Hogrefe, Göttingen - Bern - Toronto - Seattle 